Ekspansi: Jurnal Ekonomi, Keuangan, Perbankan dan Akuntansi

ISSN (Online): 2580-7668 ISSN (Print): 2085-5230

Vol. 11, No. 2 (November 2019), Hal. 211 - 222

\title{
PENGARUH SIKAP, NORMA SUBJEKTIF, KENDALI PERILAKU DAN RELIGIUSITAS TERHADAP INTENSI MENGGUNAKAN UANG ELEKTRONIK
}

\author{
Ferinaldy ${ }^{1}$, Muslikh $^{2}$, Nurul Huda ${ }^{3}$ \\ ${ }^{1,2,3}$ Magister Manajemen Universitas YARSI, Jakarta, Indonesia \\ Email Korespondensi: nurul.huda@yarsi.ac.id
}

\begin{abstract}
The purpose of this study was to examine the factors of attitude, subjective norms, behavioral control, and religiosity towards the intention to use electronic money on YARSI University students. Based on a literature review, this research hypothesis states that attitudes, subjective norms, behavioral control, and religiosity affect intention. This study uses survey data from questionnaires to 127 respondents. Hypothesis testing techniques are done by using SEM analysis with Lisrel software. The results of data processing indicate that the Attitude Variable, Subjective Norms, Behavioral Control, and Religiosity have a significant influence on the intention to use electronic money. Intention variable has a significant effect on behavior using electronic money with a $t$ value of 7.86. Behavioral Control Variables and subjective norms have a greater influence on the intention to use electronic money than other variables. Suggestions based on research results: first, it is necessary to expand information to the public about the benefits of using electronic money. Second, it is necessary to increase the number of merchants or expand the place of use so that the use of electronic money becomes more extensive and maximal.
\end{abstract}

Keywords: Intention, Electronic Money, SEM, Lisrel.

Abstrak: Tujuan penelitian ini adalah menguji faktor sikap, norma subyektif, kendali perilaku, dan religiusitas terhadap intensi untuk menggunakan uang elektronik pada mahasiswa Universitas YARSI. Berdasarkan tinjauan literatur, hipotesis penelitian ini menyatakan bahwa sikap, norma subyektif, kendali perilaku, dan religiusitas berpengaruh terhadap intensi. Penelitian ini menggunakan data hasil survey dari penyebaran kuesioner kepada 127 responden. Teknik pengujian hipotesis dilakukan dengan menggunakan analisis SEM dengan software Lisrel. Hasil pengolahan data menunjukkan bahwa Variabel Sikap, Norma Subjektif, Kendali Perilaku, dan Religiusitas memiliki pengaruh yang signifikan terhadap intensi untuk menggunakan uang elektronik. Variabel Intensi memiliki pengaruh yang signifikan terhadap perilaku menggunakan uang elektronik dengan nilai t sebesar 7,86. Variabel Kendali Perilaku dan norma subjektif memiliki pengaruh yang lebih besar terhadap intensi untuk menggunakan uang elektronik daripada variabel lain. Saran berdasarkan hasil penelitian: pertama, perlu memperluas informasi kepada masyarakat tentang manfaat penggunaan uang elektronik. Kedua, perlu peningkatan jumlah merchant atau memperluas tempat penggunaan agar pemanfaatan uang elektronik semakin luas dan maksimal.

Kata Kunci: Intensi, Uang Elektronik, SEM, Lisrel

DOI: $10.35313 /$ ekspansi.v11i2.1531

Riwayat Artikel:

Diterima: 10 - $09-2019$

Direvisi: $19-11-2019$

Disetujui: $24-11-2019$ 


\section{PENDAHULUAN}

Saat ini penggunaan uang elektronik (e-money) di Indonesia cukup tinggi khususnya di kota-kota besar. Hal ini bisa dipahami karena tingkat perputaran uang di perkotaan jauh lebih cepat dibandingkan dengan di daerah-daerah (pedesaan). Tingkat perputaran ini ditopang karena Jakarta merupakan pusat atau sentra pedagangan dengan jangkauan atau sirkulasi untuk daerah-daerah di seluruh Indonesia. Uang elektronik paling banyak digunakan di pusat kota seperti Jakarta juga karena dukungan penyebaran fasilitas pengguna untuk mengakses uang elektronik. Jakarta sudah memiliki infrastruktur sistem pembayaran yang mumpuni dan pendapatan masyarakat yang tinggi. Pertumbuhan penggunaan uang elektronik di Jakarta salah satunya didukung oleh kegiatan elektronifikasi jalan tol, kemudian diikuti tumbuhnya penggunaan ojek online dengan dukungan pembayaran melalui uang elektronik serta pembayaran transportasi umum seperti Transjakarta, kereta commuterline yang juga mengharuskan pembayarannnya melalui uang elektronik.

Gaya hidup cashless (non-tunai) di kalangan masyarakat Indonesia sudah perlahan mulai tumbuh. Penggunaan uang elektronik sudah mulai meluas dan hal ini terlihat dari semakin bertambahnya jumlah transaksi keuangan yang menggunakan uang elektronik setiap tahunnya. Di tahun 2017 tercatat terjadi 943 juta transaksi yang menggunakan uang elektronik dan di 2018, Bank Indonesia mencatat terdapat 2.923 juta transaksi menggunakan uang elektronik atau naik 210\%. Sementara dari sisi volume transaksi uang elektronik, tahun 2018 ini memasuki angka yang cukup signifikan. Hingga akhir 2018 tercatat nominal Rp. 41.199 triliun padahal ditahun sebelumnya di 2017 nominal transaksi telah meraih Rp. 12.375 triliun atau naik 281\%. Kenaikan ini cukup fantastis karena meningkat dua kali lipat pada tahun sebelumnya.

Di tahun 2019 ini, sejumlah jalur jalan tol juga sudah mempergunakan pembayaran nontunai dan disaat yang sama pusat pembelajaan yang menggunakan jasa parking mulai mewajibkan penggunakan e-money dan selanjutnya diperkirakan akan semakin inklusif dan kehadiran fintech (yang juga akan berkolaborasi dengan perbankan konvensional) akan semakin menguat. Sejalan dengan hal itu, provider sebagai penyedia layanan pembayaran digital mulai mencanangkan program agar bagaimana alat pembayaran digitalnya bisa dipakai di merchant, warung-warung dan pusat pembelajnaan yang memungkinkan menggunakan sistem pembayaran digital melalui QR code. Dengan kehadiran uang elektronik, maka akan semakin meramaikan persaingan cashless $\mathrm{QR}$ code.

Mahasiswa pada umumnya dalam menentukan tingkat konsumsinya sangat dipengaruhi oleh tingkat pendapatannya, baik dalam mengkonsumsi barang dan jasa, maupun produk perbankan seperti halnya uang elektronik. Dengan jumlah pendapatan yang rendah, mahasiswa akan mengalokasikan pendapatannya untuk pengeluaran uang elektronik dalam segi transportasi bus Transjakarta atau commuterline. Mudahnya bertransaksi keuangan secara digital akan memungkinkan kebiasaan baru bertransaksi pada generasi millenial di Indonesia dan pada akhirnya teknologi pembayaran digital saat ini semakin diarahkan untuk memberikan 
pengalaman penggunaan yang lebih mulus bagi pengguna, khususnya millenial dan penerusnya.

Universitas YARSI memiliki jumlah mahasiswa yang cukup besar yaitu mencapai 5.000 mahasiswa. Dalam aktifitas hariannya, mahasiswa banyak melakukan transaksi tunai dalam pembayaran makanan, minuman dan jajanan di kantin-kantin, pembayaran fotokopi, cetak dan pembayaran kebutuhan belanja lainnya yang pada umumnya nilai transaksinya kecil. Mengingat transaksi yang banyak terjadi di lingkungan kampus adalah transaksi yang relatif kecil (mikro) dengan itensitas yang cukup tinggi, maka dari itu uang elektronik merupakan jawaban dari kebutuhan masyarakat dalam pembayaran mikro.

Penelitian ini untuk menguji faktor sikap, norma subyektif, kendali perilaku, dan religiusitas terhadap intensi untuk menggunakan uang elektronik di mahasiswa Universitas YARSI.

\section{TINJAUAN PUSTAKA}

Uang elektronik merupakan alat pembayaran non tunai. Di dalam uang elektronik terdapat sejumlah uang tunai yang dikonversi menjadi data elektronik dan disimpan dalam server atau chip. Uang elektronik ini berfungsi sebagai alat pembayaran giral kepada pedagang yang bukan penerbit uang elektroniknya (Usman, 2017).

Pada Teori minat yang dikemukan oleh Ajzen (2012) ada tiga faktor utama penentu dari minat yaitu sikap, norma subyektif dan kendali perilaku. Sikap adalah predisposisi yang dipelajari dalam merespon secara konsisten sesuatu objek, dalam bentuk suka atau tidak suka (Schiffman \& Kanuk, 2010). Ada 4 indikator dalam menilai sikap terhadap penggunaan uang elektronik yakni karena diinginkan, berguna, baik dan menyenangkan.

Norma subyektif merupakan kecenderungan yang dipelajari dari konsumen melalui keyakinannya bahwa referen berpikir tentang sesuatu yang akan dilakukan oleh konsumen. Referen dapat berupa anggota keluarga, teman, sahabat, atasan, bawahan dan seorang ahli (Schiffman \& Kanuk, 2010). Nugroho (2018) menggunakan empat acuan dalam penilaian norma subjektif terhadap penggunaan uang elektronik sebagai alat pembayaran yakni pengaruh anjuran anggota keluarga, rekan (teman), lingkungan sosial dan anjuran guru/dosen.

Ajzen (2012) menyatakan bahwa variabel persepsi kendali perilaku adalah sebagai seberapa jauh seseorang percaya atau merasa mampu untuk melakukan sesuatu. Variabel kendali perilaku ini ditentukan oleh keyakinan individu mengenai kekuatan faktor eksternal dan faktor internal untuk memfasilitasi perilaku. Nugroho (2018) menggunakan tiga indikator penilaian kendali perilaku terhadap penggunaan uang elektronik sebagai alat pembayaran yakni karena mengetahui manfaatnya, dapat digunakan untuk berbagai transaksi pembayaran dan mempunyai jaringan merchant yang luas dan mudah ditemukan.

Hubungan Religiusitas terhadap perilaku pembelian adalah hal yang penting karena perusahaan akan lebih mampu memahami kebutuhan spesifik pelanggan mereka (Khraim, 2010). Hasil penelitian tersebut mendukung Religiusitas 
berpengaruh pada perilaku yang bergantung pada tingkat Religiusitasnya (Souiden et al., (2015); Khraim, 2010). Maka hal ini menjadi celah penelitian Religiusitas dan TPB (Azam, 2016; Alam dan Sayuti, 2011) secara langsung dengan perilaku konsumen. Religiusitas berpengaruh negatif pada perilaku (Jahwari, 2016). Religiusitas dan norma subyektif tidak signifikan dalam mempengaruhi niat pembelian (Azam, 2016). Ada ketidakkonsistenan pengaruh Religiusitas terhadap perilaku dan niat pembelian. Peran Religiusitas pada perilaku harus diteliti lebih lanjut.

Selanjutnya intensi (niat perilaku) merupakan kekuatan utama yang menjadi sumber motivasi seseorang untuk bertingkah laku tertentu. Semakin kuat intensi untuk melakukan tingkah laku tertentu, maka semakin besar kemungkinannya untuk melakukan tingkah laku tersebut (Ajzen, 2012). Variabel intensi masyarakat meliputi 3 bagian yaitu: berniat menggunakan, mencoba menggunakan dan berencana menggunakan. Perilaku konsumen menurut Solomon (2011) adalah studi tentang proses yang terlibat ketika individu atau kelompok memilih, membeli, menggunakan atau menghabiskan barang, jasa, ide atau pengalaman untuk memuasakan kebutuhan dan keinginan. Ada tiga indikator yang melandasinya yakni prinsip moralitas, prinsip kemurahan hati dan prinsip kesederhanaan.

\section{METODE PENELITIAN}

Populasi dalam penelitian ini adalah mahasiswa Universitas YARSI. Teknik pengambilan sampel menggunakan Maximum Likelihood Estimation (MLE). Jumlah sampel yang digunakan dalam penelitian ini disesuaikan dengan metode analisis yang digunakan yaitu Structural Equation Model (SEM). Dalam metode Structural Equation Model (SEM), jumlah sampel yang dibutuhkan paling sedikit 5 kali jumlah variabel indikator (Ferdinand, 2014) dan dalam penelitian ini terdiri dari 22 indikator maka jumlah sampel yang dibutuhkan adalah minimal 110. Pada penelitian ini sampel berjumlah 127 .

Adapun data untuk melihat hubungan variabel laten dilakukan dengan menggunakan kuesioner five-point Likert scale di mana (1) untuk pilihan "Sangat Tidak Setuju" hingga (5) Sangat Setuju". Sementara untuk pertanyaan demografi menggunakan pilihan berganda. Adapun indikator pertanyaan atau variabel pengukuran dalam penelitian ini diadaptasi dari beberapa sumber. Data dianalisis dengan menggunakan SEM dan menggunakan software LISREL for WINDOWS 8.80. SEM merupakan teknik regresi yang dilakukan secara simultan dan umum digunakan untuk mengukur variabel yang abstrak (tidak berwujud sehingga tidak dapat diamati langsung melalui panca indera).

Keunggulan utama SEM adalah kemampuannya untuk mengestimasi para meter dalam model jalur sementara mengoreksi pengaruh bias dari kesalahan pengukuran yang random. Tidak seperti prosedur analisis multivariat tradisional (seperti analisis regresi atau path analysis) yang tidak mampu mengestimasi atau mengoreksi kesalahan pengukuran, SEM secara eksplisit memberikan estimasi terhadap varian kesalahan tersebut. 


\section{HASIL DAN PEMBAHASAN}

Penelitian ini mengukur enam variabel, yaitu Niat perilaku (intensi) (Y1), Perilaku (Y2), sikap (X1), norma subjektif (X2), kendali perilaku (X3), dan religiusitas (X4) yang dilakukan pada 127 orang responden. Setiap variabel diukur secara terpisah melalui instrumen penelitian yang berupa kuesioner berdasarkan metode skala likert dan data ordinal.

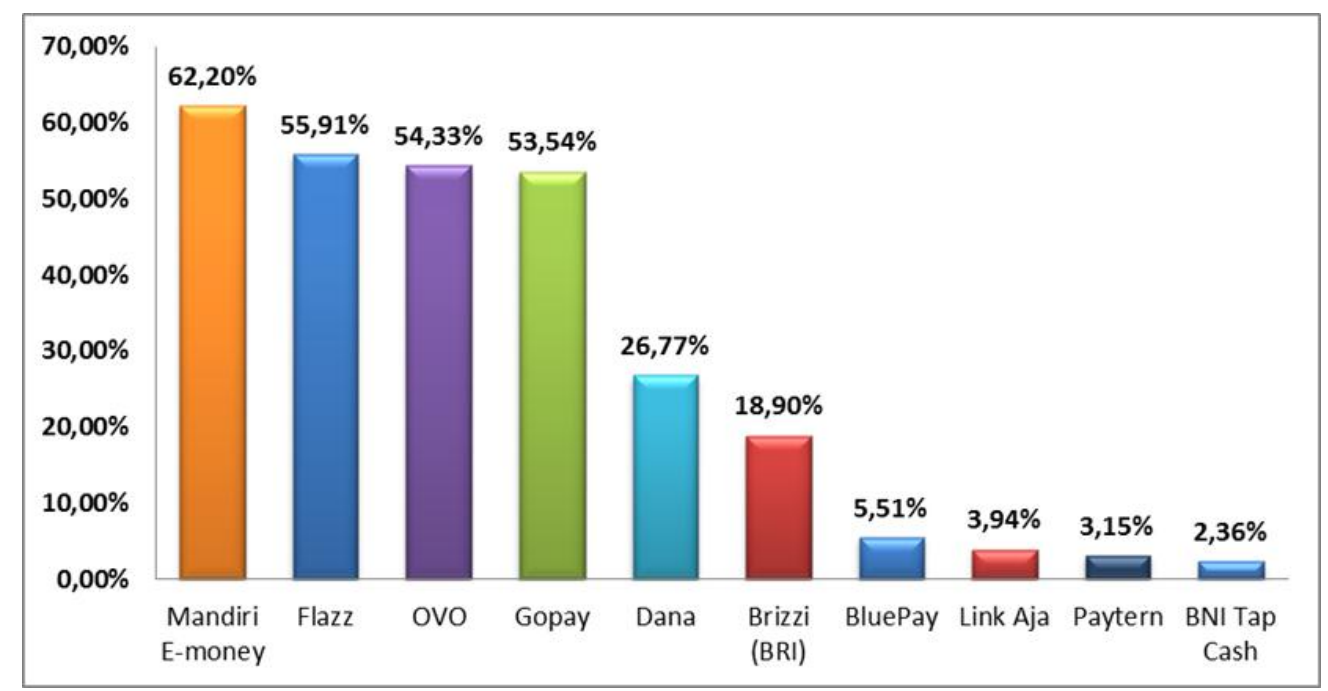

Sumber: Kuesioner penelitian, data diolah (2019)

Gambar 1. Diagram Batang Produk Uang Elektronik yang Digunakan

Berdasarkan gambar di atas dapat diketahui bahwa mayoritas sebaran responden yang menjadi sampel dalam penelitian ini menggunakan kartu Mandiri E-money sebanyak 62,2\%, kemudian disusul oleh kartu Flazz BCA 55,91\%. Untuk produk non kartu, OVO (54,33\%) dan Gopay (53,54\%) saling bersaing mendominasi dengan perbedaan hanya $0,79 \%$. Produk uang elektronik lainnya masih kecil dan berada di bawah 10\% yakni BluePay (5,51\%), Link Aja (3,94\%), Paytern (3,15\%) dan BNI Tapcash (2,36\%). Hal ini menunjukkan bahwa sebagian besar sebaran responden berasal dari mereka yang menggunakan e-money Mandiri dan pengguna uang elektronik OVO.

Produk uang elektronik kartu Mandiri e-money digunakan mayoritas responden karena tampilannya dan manfaatnya bisa disesuaikan dengan kebutuhan para nasabahnya. Contohnya, e-Money dengan menggandeng minimarket seperti Indomaret Card, kemudian kerjasama dengan Pertamina dengan mengeluarkan kartu edisi GazCard. Kartu ini dapat digunakan untuk pembayaran Transjakarta, tol, tiket kereta, parkir, ataupun restoran yang terdapat logo e-Money. Kartu Flazz BCA mempunyai fasilitas dan manfaat yang sama dengan kartu uang elektronik yang dikeluarkan bank Mandiri. Kedua bank ini paling banyak digunakan dalam uang elektronik karena ketersediaan infrastructure pendukung seperti alat tapping serta kemudahan isi ulang walaupun bukan nasabah bank tersebut.

OVO, Gopay dan Dana menjadi mayoritas digunakan responden karena saat ini program tawaran diskon yang disajikan sangat menarik setiap harinya. Keunggulan terbesar produk ini ialah untuk mengisi saldo uang elektronik, responden tidak 
diharuskan mempunyai akun perbankan atau rekening. Cukup melalui minimarket atau pihak yang telah bekerja sama. Sehingga kedepannya produk keuangan ini dapat menjadi saingan berat dalam hal transaksi keuangan. Namun produk non kartu ini mempunyai kelemahan karena responden harus mempunyai perangkat smartphone, sehingga saat ini pusat penyebarannya masih berada di pusat kota disetiap daerah.

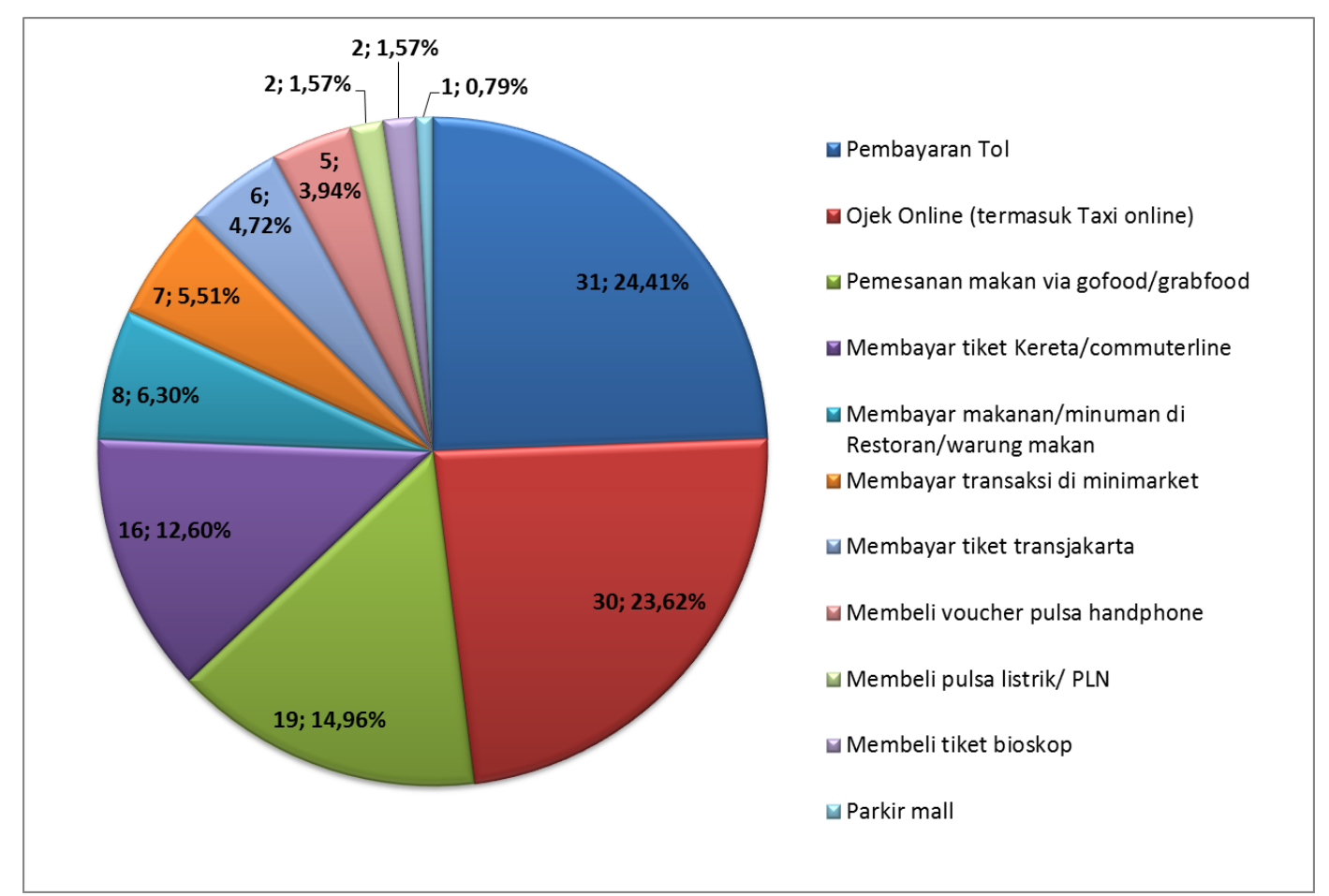

Sumber: Kuesioner penelitian, data diolah (2019)

Gambar 2. Diagram Lingkaran Jenis Transaksi Yang Digunakan Responden

Berdasarkan gambar di atas dapat diketahui bahwa mayoritas sebaran responden yang menjadi sampel dalam penelitian ini adalah responden dengan penggunaan uang elektronik untuk jenis pembayaran tol sebanyak 31 responden $(24,41 \%)$, dan disusul dengan pembayaran transaksi ojek online, yaitu sebanyak 30 responden $(23,62 \%)$. Posisi selanjutnya dengan responden yang menggunakan untuk transaksi pemesanan makanan via ojek online sebanyak 19 orang (14,96\%) dan untuk pembayaran tiket commuter/kereta sebanyak 16 orang (12,60\%). Jumlah responden yang paling rendah menggunakan uang elektronik untuk transaksi membeli tiket bioskop hanya sebanyak dua orang $(1,57 \%)$ dan pembayaran parkir mall hanya sebanyak satu responden $(0,79 \%)$. Hal ini menunjukkan bahwa sebagian besar sebaran responden menggunakan untuk kebutuhan pendukung transportasi (tol), Transjakarta, commuterline (kereta api) dan menggunakan untuk transportasi berbasis ojek online. Dengan semakin beragam pemanfaatan uang elektronik, maka aktivitas responden menjadi lebih mudah cepat dan terlayani.

Hasil penelitian Handayani (2015) dalam perilaku masyarakat ketika membeli tiket transportasi ternyata lebih puas menggunakan uang elektronik dibandingkan menggunakan uang tunai. Dengan semakin meningkatnya kepuasan masyarakat maka pada akhirnya akan meningkatkan volume transaksi uang elektronik dan mempercepat 
cash less society. Selanjutnya hasil penelitian Setyo dan Dede (2015) mengevaluasi penggunaan uang elektronik di sistem ticketing commuterline, mendapatkan bahwa secara umum setiap pengguna jasa commuterline sebagai responden pada penelitian ini mayoritas positif. Sikap responden pada persepsi manfaat mayoritas positif. Artinya masyarakat masih mengutamakan kemanfaatan dalam hal dapat membuat pekerjaan mereka menjadi mudah.

Tabel 1. Goodness of Fit Structural Equation Model (SEM)

\begin{tabular}{|c|c|c|c|}
\hline Ukuan GOF & Tingkat Kecocokan & Hasil Estimasi & Tingkat Kecocokan \\
\hline Chi Square & Nilai yang kecil & 380.15 & \multirow{2}{*}{ Bad Fit } \\
\hline Pvalue & $P>0,05$ & 0.000 & \\
\hline $\mathrm{NCP}$ & Nilai yang kecil & 148.79 & \multirow{2}{*}{ Bad Fit } \\
\hline Interval & Interval yang sempit & $101.36 ; 204.07$ & \\
\hline RMSEA & RMSEA $<0,08$ & 0.079 & Good Fit \\
\hline \multirow{3}{*}{ ECVI } & \multirow{3}{*}{$\begin{array}{l}\text { Nilai yang kecil dan dekat } \\
\text { dengan ECVI saturated }\end{array}$} & $\mathrm{M}=3.7$ & \multirow{3}{*}{ Good Fit } \\
\hline & & $S=4.02$ & \\
\hline & & $\mathrm{I}=49.2$ & \\
\hline \multirow{3}{*}{ AIC } & \multirow{3}{*}{$\begin{array}{l}\text { Nilai yang kecil dan dekat } \\
\text { dengan AIC saturated }\end{array}$} & $M=465.79$ & \multirow{3}{*}{ Good Fit } \\
\hline & & $\mathrm{S}=506$ & \\
\hline & & $\mathrm{I}=6199.38$ & \\
\hline \multirow{3}{*}{ CAIC } & \multirow{3}{*}{$\begin{array}{l}\text { Nilai yang kecil dan dekat } \\
\text { dengan CAIC saturated }\end{array}$} & $M=711.82$ & \multirow{3}{*}{ Good Fit } \\
\hline & & $S=1478.58$ & \\
\hline & & $I=6283.95$ & \\
\hline NFI & $>0,90$ & 0.94 & Good Fit \\
\hline NNFI & $>0,90$ & 0.96 & Good Fit \\
\hline $\mathrm{CFI}$ & $>0,90$ & 0.97 & Good Fit \\
\hline IFI & $>0,90$ & 0.97 & Good Fit \\
\hline $\mathrm{CN}$ & $\mathrm{CN}>200$ & 79.6 & Bad Fit \\
\hline SRMR & $<0,05$ & 0.085 & Bad Fit \\
\hline CFI & $>0,90$ & 0.97 & Good Fit \\
\hline GFI & $>0,90$ & 0.8 & Marginal Fit \\
\hline
\end{tabular}

Sumber : Kuesioner penelitian, data diolah (2019)

Pada Tabel diatas ada empat indikator GOF yang tergolong bad fit (kurang baik), sembilan indikator GOF good fit (kecocokan yang baik) dan satu indikator GOF marginal fit (kecocokan yang cukup baik). Sehingga dapat disimpulkan model penelitian secara keseluruhan tergolong cocok (fit). 
Tabel 2. Reliabilitas Model Pengukuran

\begin{tabular}{|l|c|c|c|}
\hline \multirow{2}{*}{ Variabel } & \multicolumn{2}{|c|}{ Reliabilitas } & \multirow{2}{*}{ Keterangan } \\
\cline { 2 - 3 } & CR $\geq 0,70$ & VE $\geq 0,50$ & \\
\hline Sikap & 0.89 & 0.66 & Reliabilitas Baik \\
\hline Norma Subjektif & 0.89 & 0.68 & Reliabilitas Baik \\
\hline Kendali Perilaku & 0.81 & 0.59 & Reliabilitas Baik \\
\hline Religiusitas & 0.89 & 0.61 & Reliabilitas Baik \\
\hline Niat Perilaku & 0.97 & 0.91 & Reliabilitas Baik \\
\hline Perilaku & 0.81 & 0.59 & Reliabilitas Baik \\
\hline
\end{tabular}

Sumber: Kuesioner penelitian, data diolah (2019)

Tabel 2 yang merupakan nilai reliabilitas model pengukuran dilihat dari nilai CR dan VE, menunjukkan bahwa semua model pengukuran dalam penelitian ini adalah reliable atau andal untuk mengukur sikap, norma subjektif, kendali perilaku, religiusitas niat perilaku, dan perilaku. Hal ini terlihat dari nilai CR dan VE variabel penelitian yang ada, bahwa semua variabel memiliki nilai $\mathrm{CR}>0,70$ dan nilai $\mathrm{VE}>$ 0,50, sehingga model pengukuran dalam penelitian ini andal untuk mengukur variabel sikap, norma subjektif, kendali perilaku, religiusitas niat perilaku, dan perilaku.

Tabel 3. Evaluasi Terhadap Koefisien Model Struktural

\begin{tabular}{|c|l|c|c|l|}
\hline Hipotesis & \multicolumn{1}{|c|}{ Hubungan } & Estimasi Standar & t-hitung & Keterangan \\
\hline 1 & Niat Perilaku $\leftarrow$ Sikap & 0.24 & 2.21 & Significant \\
\hline 2 & Niat Perilaku $\leftarrow$ Norma Subjektif & 0.20 & 2.70 & Significant \\
\hline 3 & Niat Perilaku $\leftarrow$ Kendali Perilaku & 0.38 & 3.03 & Significant \\
\hline 4 & Niat Perilaku $\leftarrow$ Religiusitas & 0.19 & 2.57 & Significant \\
\hline 5 & Perilaku $\leftarrow$ Niat Perilaku & 0.74 & 7.86 & Significant \\
\hline
\end{tabular}

Sumber: Kuesioner penelitian, data diolah (2019)

Berdasarkan tabel di atas secara keseluruhan bahwa hasil hipotesis model penelitian, diperoleh hasil output berupa tvalue semua hipotesa lebih besar dari 1.96, maka dapat disimpulkan bahwa variabel sikap, norma subjektif, kendali perilaku, religiusitas, berpengaruh positif dan signifikan terhadap niat perilaku, dan variabel niat perilaku berpengaruh positif dan signifikan terhadap perilaku mahasiswa Universitas YARSI dalam menggunakan uang elektronik.

Pada hipotesis 1 hasil t-value adalah 2.21 lebih besar dari 1.96, maka dapat disimpulkan bahwa variabel Sikap berpengaruh positif sebesar 0.24 terhadap niat perilaku secara signifikan. Dengan demikian, hipotesis 1 dapat diterima dan dapat disimpulkan bahwa semakin baik sikap yang dirasakan mahasiswa, maka niat perilakunya akan semakin baik pula. Hasil yang sama diperoleh dalam penelitian Yudhi dan Novi (2015), Cruz et. al. (2015), Pratiwi et. al., (2015), Irawan et. al. (2016), Fatmasari dan Wulandari (2016), Ariyanto (2018), Darmadi et. al., (2018), Annisa (2018), dan Wahyuningsih (2018) bahwa sikap berpengaruh positif signifikan terhadap minat perilaku. Hasil ini berbeda dengan Nugroho (2018) yang mendapatkan bahwa Mahasiswa IPB dalam penggunaan uang elektronik, menunjukkan bahwa variabel sikap tidak berpengaruh signifikan terhadap minat.

Pada hipotesis 2 hasil t-value adalah 2.70 lebih besar dari 1.96, maka dapat disimpulkan bahwa variabel norma subjektif berpengaruh positif sebesar 0.2 terhadap 
niat perilaku secara signifikan. Dengan demikian, hipotesis 2 dapat diterima dan dapat disimpulkan bahwa semakin baik norma subjektif yang dirasakan mahasiswa, maka niat perilakunya akan semakin baik pula. Hasil serupa didapat pada penelitian Yudhi \& Novi (2015), Farida dan Mahmud (2015), Cruz et. al. (2015), Pratiwi et. al., (2015), Irawan et. al. (2016), Fatmasari dan Wulandari (2016), Nugroho (2018), Anjelina (2018), Ariyanto (2018), Darmadi et. al., (2018), dan Wahyuningsih (2018). Peran norma subjektif sangat penting dalam pelaksanaan uang elektronik di Indonesia karena masyarakat menggunakan uang elektronik agar memberikan nilai tambah dalam meningkatkan reputasi sosial. Jika lingkungan keluarga, teman dan sekitarnya menggunakan uang elektronik e-money, maka ia akan terdorong untuk menggunakannya juga.

Pada hipotesis 3 hasil t-value adalah 3.03 adalah lebih besar dari 1.96, maka dapat disimpulkan bahwa variabel kendali perilaku berpengaruh positif sebesar 0.38 terhadap niat perilaku secara signifikan. Dengan demikian, hipotesis 3 dapat diterima dan dapat disimpulkan bahwa semakin baik kendali perilaku yang dirasakan mahasiswa, maka niat perilakunya akan semakin baik pula. Hasil yang sama diperoleh dalam penelitian Cruz et. al. (2015), Farida dan Mahmud (2015), Pratiwi et. al., (2015), Fatmasari dan Wulandari (2016), Irawan et. al. (2016), Nugroho (2018), Ariyanto (2018), Darmadi et. al., (2018), dan Wahyuningsih (2018). Kendali perilaku positif terhadap niat perilaku menerangkan bahwa masyarakat pengguna uang elektronik memiliki pengetahuan, kemampuan dan sumber yang baik yang pada akhirnya mempengaruhi minat masyarakat dalam menggunakan uang elektronik.

Pada hipotesis 4 hasil t-value adalah 2.57 lebih besar dari 1.96, maka dapat disimpulkan bahwa variabel religiusitas berpengaruh positif sebesar 0.19 terhadap niat perilaku secara signifikan. Dengan demikian, hipotesis 4 dapat diterima dan dapat disimpulkan bahwa semakin baik religiusitas yang dirasakan mahasiswa, maka niat perilakunya akan semakin baik pula. Hasil penelitian ini juga didukung pada penelitian Nur'aini (2019), Mariana (2019), dan Destriyanto dan Setiawan (2019). Hasil yang berbeda didapat Rizqa (2019) yang mendapatkan hasil bahwa variabel religiusitas memiliki pengaruh negatif terhadap pengeluaran konsumsi masyarakat. Selanjutnya Bawono (2014) menyebutkan bahwa seorang muslim yang memiliki religiusitas yang tinggi, maka dia akan semakin mempertimbangkan prospek ke depan dengan lebih baik termasuk kehidupan dunia dan juga balasan yan ia terima diakhirat kelak. Oleh sebab itu, pengeluaran konsumsi seorang muslim untuk memenuhi kebutuhan orang lain (sedekah) merupakan investasi dengan daya pikat tinggi. Investasi dalam bentuk sedekah dapat memberikan keuntungan dan berkah.

Pada hipotesis 5 hasil t-value adalah lebih besar dari 1.96, maka dapat disimpulkan bahwa variabel niat perilaku berpengaruh positif sebesar 0.74 terhadap perilaku secara signifikan. Dengan demikian, hipotesis 5 dapat diterima dan dapat disimpulkan bahwa semakin baik niat perilaku yang dirasakan mahasiswa, maka perilakunya akan semakin baik pula. Hasil penelitian ini juga didukung dari penelitian sebelumnya oleh Pratiwi et. al. (2015), Firdauzi (2017), Huda (2018), dan Darmadi et. al. (2018) bahwa terdapat hubungan yang positif dan signifikan antara niat perilaku dangan perilaku terhadap 
produk uang elektronik e-money. Hal yang sama juga di temukan pada penelitian Grupta \& Dogra (2017) bahwa keputusan individu untuk melakukan suatu perilaku ditentukan oleh niat untuk melakukan. Niat berperan penting dalam menentukan tindakan manusia. Dengan demikian semakin kuat niat mahasiswa untuk melakukan perilaku menggunakan uang elektronik, maka besar kemungkinan niat tersebut diaktualisasikan dalam bentuk perilaku .

\section{PENUTUP}

Berdasarkan hasil penelitian disimpulkan bahwa Variabel sikap berpengaruh positif dan signifikan terhadap niat perilaku sehingga bahwa semakin baik Sikap yang dirasakan mahasiswa Universitas YARSI, maka niat perilakunya akan semakin baik pula. Variabel norma subjektif berpengaruh positif dan signifikan terhadap niat perilaku, sehingga semakin baik norma subjektif yang dirasakan mahasiswa Universitas YARSI maka niat perilakunya akan semakin baik pula.

Variabel kendali perilaku berpengaruh positif dan signifikan terhadap niat perilaku, sehingga semakin baik kendali perilaku yang dirasakan mahasiswa Universitas YARSI maka niat perilakunya akan semakin baik pula. Variabel religiusitas berpengaruh positif dan signifikan terhadap niat perilaku, sehingga semakin baik religiusitas yang dirasakan mahasiswa Universitas YARSI maka niat perilakunya akan semakin baik pula.

Penelitian ini masih memiliki beberapa keterbatasan, adapun keterbatasan penelitian ini mengenai sample reponden, yaitu untuk penelitian selanjutnya agar dapat lebih spesifik sample penelitian untuk program studi tertentu agar lebih menjelaskan data karakteristik dari responden. Selain itu peneliti berikutnya agar dapat menambahkan variabel lain dan faktor-faktor yang dapat mempengaruhi keputusan mahasiswa dalam menggunakan uang elektronik dalam menunjang aktivitas belajar dan kehidupan sehari-hari.

\section{DAFTAR PUSTAKA}

Ajzen, I. 2012. The theory of planned behavior. In P. A. M. Lange, A. W. Kruglanski \& E. T. Higgins (Eds.), Handbook of theories of social psychology (Vol. 1, pp. 438-459). London, UK: Sage

Alam, S.S. and Sayuti, N.M. 2011. Applying the theory of planned behavior (TPB) in halal foodpurchasing”. International Journal of Commerce and Management, 21 (1): $8-20$

Anjelina. 2018. Persepsi Konsumen Pada Penggunaan E-Money. Journal Of Applied Managerial Accounting 2 (2): 219-231

Annisa, S. N. Amalia. 2018. Faktor-Faktor Yang Mempengaruhi Minat Individu Terhadap Financial Technology (Fintech) Syariah (Paytren) Sebagai Salah Satu Alat Transaksi Pembayaran (Pendekatan Technology Acceptance Model dan Theory Of Planned Behavior. Iqtishaduna Jurnal Ekonomi dan Keuangan Islam. 9 (1) : $57-73$ 
Ariyanto, Debby. 2018. Pengaruh Attitude, Subjective Norm, Dan Perceived Behavioral Control Terhadap Repurchase Intention E-Money. Jurnal Ilmu Manajemen Jurusan Manajemen Fakultas Ekonomi Universitas Negeri Surabaya. 6 (4) : 583-589

Azam, A. 2016. An empirical study on non-Muslim's packaged halal food manufacturers. Journal of Islamic Marketing, 7(4), 441-460.

Bawono, Anton. 2014. Kontribusi Religiusitas dalam Rasionalitas Konsumsi Rumah Tangga Muslim. Inferensi, Jurnal Penelitian Sosial Keagamaan. 8 (2) : 287-308.

Cruz, L., Suprapti N. W. S., dan Yasa N. Y. K. 2015. Aplikasi Theory Of Planned Behavior Dalam Membangkitkan Niat Berwirausaha Bagi Mahasiswa Fakultas Ekonomi Unpaz, Dili Timor Leste. EJurnal Ekonomi dan Bisnis Universitas Udayana. 4 (12) : 895-920.

Darmadi S.S. Syamsul M.M. dan Sukmawati M. 2018. Analysis Of Factors Affecting People's Behavior In Using Electronic Payment Instruments. Jurnal Organisasi dan Manajemen, 14 (2) : 108-119

Destriyanto, E. Pristi, dan Setiawan, F. 2019. Analisis Faktor Pendapatan Dan Religiusitas Dalam Mempengaruhi Minat Muzakki Dalam Membayar Zakat Profesi. Jurnal Analisis Bisnis Ekonomi, 17 (1) : 32-43

Farida, I., dan Mahmud. 2015. Pengaruh Theory Planned Of Behavior Terhadap Intensi Berwirausaha Mahasiswa - Jurnal Ilmiah STIE MDP. 5 (1) : 37-45

Fatmasari, D. \& Wulandari, S. 2016. Analisis Faktor Faktor Yang Mempengaruhi Minat Mahasiswa Dalam Penggunaan APMK - Al-Mustashfa: Jurnal Penelitian Hukum Ekonomi Syariah. 4 (1) : 93-103

Ferdinand, Augusty. 2014. Metode Penelitian Manajemen. BP Universitas Diponegoro. Semarang.

Firdauzi, Indrawan. 2017. Pengaruh Kemampuan Finansial, Kemudahan, dan Perilaku Konsumen Terhadap Minat Penggunaan Uang Elektronik Di Kota Yogyakarta. Jurnal Pendidikan dan Ekonomi Fakultas Ekonomi Universitas Negeri Yogyakarta. 6 (1): $77-87$

Grupta, A. dan Dogra, N. 2017. Tourist Adoption of Mapping Apss: A UTAUT2 Perspective of Smart Travellers. Journal Tourism and Hospitality Management. 23 (2): $145-161$.

Handayani, L. 2015. Analisis preferensi penggunaan uang elektronik pada kereta api commuter JABODETABEK. Jurnal Ilmiah Mahasiswa Fakultas Ekonomi dan Bisnis Universitas Brawijaya 4 (1)

Huda, Nurul; Hulmansyah, Rini. 2018. Faktor Yang Mempengaruhi Perilaku Konsumsi Produk Halal Pada Kalangan Mahasiswa Muslim. Ekuitas: Jurnal Ekonomi dan Keuangan. 2 (2) : 247 - 270

Irawan, H., Hendayani, R., dan Widyan, D., 2016. Adoption of Electronic Toll Application Analysis. International Journal of Economics and Management 10 (1): 211 $-222$ 
Jahwari, Dawood Sulaiman Al. 2016. “An Integrative Model of Muslim Students' Religiosity dan Travelling Behavior to Gaming Destinations". Disertasi, California: Proquest.

Khraim, H. 2010. "Measuring Religiosity in Consumer Research from Islamic Perspective.” International Journal of Marketing Studies. 2 (2) : 166-179.

Mariana D. Lestari. 2019. Pengaruh Kelebihan Penghasilan Dan Religiusitas Terhadap Intensi Masyarakat Desa Takeranklating Tikung Lamongan Untuk Menjadi Nasabah Di Perbankan Syariah. Jurnal Ekonomi Syariah. 3 (2) : 172-186

Nugroho, Anton. 2018. Factors Affecting Consumers Interst in Electronic Money Usage With Theory of Planned Behavior (TPB). Journal of Consumer Sciences 3 (1) $: 15-27$.

Nur'aini I. R. 2019. Analisis Pengaruh Tingkat Religiusitas, Pengetahuan Dan Lingkungan Sosial Terhadap Minat Menabung Mahasiswa Di Bank Syariah Kota Malang. Jurnal Ilmiah Riset Manajemen. 8 (19) : 79-87

Pratiwi, E. F., Subekti,I., dan Fuad, A. 2015. Determinan Perilaku Nasabah Pengguna Mobile Banking: Model Decomposed Theory Of Planned Behavior. Ekuitas: Jurnal Ekonomi dan Keuangan. 19 (3) : 378 - 396

Rizqa, M. Khairi. 2019. Analisis Penggunaan Alat Pembayaran Menggunakan Kartu (APMK) dan E-Money terhadap konsumsi masyarakat di Banda Aceh. Jurnal Ilmiah Mahasiswa Ekonomi Islam. 1 (1)

Schiffman, L., \& Kanuk, L. 2010. Consumer Behavior (10th ed.). USA: Pearson.

Setyo Ferry Wibowo dan Dede Rosmauli. 2015. Pengaruh Persepsi Manfaat, Persepsi Kemudahan, Fitur Layanan, Dan Kepercayaan Terhadap Minat Menggunakan EMoney Card (Studi Pada Pengguna Jasa Commuterline Di Jakarta). Jurnal Riset Manajemen Sains Indonesia (JRMSI) | 6 (1).

Solomon, Michael R. 2011. Consumer Behavior (Buying, Having, and Being). New Jersey: Pearson.

Souiden, Nizar, dan Yosr Jabeur. 2015. "The impact of Islamic beliefs on consumers' attitudes dan purchase intentions of life insurance." International Journal of Bank Marketing 33 (4) : 423-441.

Usman, R. 2017. Karakteristik uang elektronik dalam sistem pembayaran. Jurnal Yuridika: Fakultas Hukum Airlangga. 32 (1)

Wahyuningsih, I. 2018. Intensi Konsumen Terhadap Kosmetik Dan Produk Skincare Halal Di Indonesia: Pendekatan Theory Of Planned Behavior. Journal of Economics and Business Aseanomics (JEBA). 3 (1) : $41-59$

Yudhi W. Arthana R., dan Novi R. 2015. Pengaruh Minat Individu Terhadap Penggunaan Mobile Banking (M-Banking): Model Kombinasi Technology Acceptance Model (TAM) Dan Theory Of Planned Behavior (TPB). Jurnal Informasi. $7(1): 25-44$ 